\title{
FROM THE DEFINITION OF USER EXPERIENCE TO A FRAMEWORK TO CLASSIFY ITS APPLICATIONS IN DESIGN
}

\author{
Berni, Aurora; \\ Borgianni, Yuri \\ Free University of Bozen-Bolzano
}

\begin{abstract}
The concept of User Experience (UX) dates back to the 1990s, but a shared definition of UX is not available. As design integrates UX, different interpretations thereof can complicate the possibility to build upon previous literature and develop the field autonomously. Indeed, by analysing the literature, UX emerges as a cauldron of related and closely linked concepts. However, it is possible to find recurring attributes that emerge from those definitions, which are ascribable to two foci: the fundamental elements of the interaction (user, system, context) and typologies of experience (ergonomic, cognitive, and emotional). Those are used to build a framework. We have preliminarily investigated how UX is dealt with in design by mapping a sample of UX-related experimental articles published in design journals. We classified UX case studies based on the framework to individuate the UXs that emerge most frequently and the most studied ones in the design field. The two-focus framework allows the mapping of experiments involving UX in design, without highlighting specific favorable combinations. However, comprehensive studies dealing with all elements and UX typologies have not been found.
\end{abstract}

Keywords: Experience design, User centred design, Emotional design, User experience, Framework

\section{Contact:}

Berni, Aurora

Free University of Bozen-Bolzano

Science and Technology

Italy

aurora.berni@natec.unibz.it

Cite this article: Berni, A., Borgianni, Y. (2021) 'From the Definition of User Experience to a Framework to Classify its Applications in Design', in Proceedings of the International Conference on Engineering Design (ICED21), Gothenburg, Sweden, 16-20 August 2021. DOI:10.1017/pds.2021.424 


\section{INTRODUCTION}

Norman introduced the term "User experience" (UX) for the first time in 1995 regarding human interface research and application (Norman et al., 1995). In its original meaning, UX is intended as the experience between a human being and a system, also regarding many aspects that go beyond the "human interface" or "usability". According to Norman, the understanding of users' needs is the core of an ideal UX; designers should fulfil those needs providing users with a smooth human-product interaction without negative feelings such as frustration and anger. Simplicity of use ranges among the means to achieve what Norman termed "joy to use". To pursue this goal, an interdisciplinary approach is necessary requiring the joint efforts of people from the fields of engineering, marketing, graphics, industrial design, and interface design.

The need to study UX in a multidisciplinary way shows how complex and multifaceted the concept of UX is. Such a complex discipline is difficult to define. Numerous attempts to find a shared definition of UX have been made through workshops like "Towards a UX manifesto" (Law et al., 2008), seminars (Roto et al., 2010) and surveys (Law et al., 2009). However, the definition of UX is still vague because of several acceptations with different nuances despite the presence of similarities.

The objective of the paper is to contribute to add clarity to the concept of UX, markedly as regards UX in design. To this end, the authors have summarized some recurring patterns in UX definitions and individuated two foci of interest for UX accordingly: pillars and different typologies of experience. An in-depth description of the two foci is provided in Section 2, which lays bare that pillars include the user, the system, and the context of use, while the typologies of experience comprise ergonomic, cognitive, and emotional UX. Around these foci, the authors propose a tentative framework (Section 2) which is then used to assess its suitability to describe experiments in product and engineering design (Section 3). As such, the framework is a candidate reference for easing the review of UX applications in design in future research. The outcomes of the study are commented in Section 4, while conclusions are drawn in Section 5.

\section{DEFINITIONS OF USER EXPERIENCE: A BACKGROUND}

The first UX acceptation reported in Section 1 is extended by several revisions of Norman's previous works, in order to stress the importance of all those factors belonging to the sphere of affection and emotions that are hidden behind the idea of "joy to own" (Sun and Teng, 2017).

The aspect of how the user feels during the interaction with a system is strengthened also by Hassenzahl and Tractinsky (2006). The scholars refer to UX as a combination of factors that involve the user (e.g. predispositions, expectations, needs, motivation, and mood), the designed system (e.g. complexity, purpose, usability, and functionality) and the context or the environment within which the interaction takes place.

The relationship and the interaction between humans and products or artifacts have been interpreted differently by some scholars. Among them, the paradigm consumer-possession (Belk, 1988) is oriented to analyse the consumer behaviour from a marketing perspective.

Other scholars assign a wider meaning to the human interaction with a technology (McCarthy and Wright, 2004). From this starting point, the scholars develop a framework where four threads are identified: sensual, emotional, compositional and spatio-temporal, which should help researchers and designers to clarify the concept of technology as experience. These threads refer to the sensory engagement and perception aspect of an experience, where emotions depend strongly on the situation or the event where the human-technology interaction takes place. The scholars consider engagement and emotions so powerful that can influence the perception of space and time. Technology as experience is compositional because it provides a set of action possibilities, where different actions can lead to different consequences.

This vision is not endorsed by Hassenzahl (2010), who claims that although technology and interactive products are the mediators of the experience, they cannot be identified as experiences themselves.

Battarbee and Koskinen (2005) consider UX as a collective phenomenon defining it as co-experience. They also see it as a kick-start for new opportunities in design for UX, where the interaction between a group of people and technology can be transposed as an input for the design of product and services.

By considering the variety of definitions of UX and all their different nuances, it is difficult to get a shared vision on this topic (Law et al., 2008). Norman himself, in an interview (Merholz, 2007), admits that his first definition of UX was overused at the point that it has been misinterpreted. The 
biggest mistake, according to Norman, is to consider UX just as the designed product (e.g. the interface of a web app) and not as a whole system. Interface design is an important component of UX (Yu and Kong, 2016) but it is often considered only from a graphical point of view, which includes appearance and aesthetic factors only (Karvonen, 2000). Also, the term "UX designers" to identify those designers who just dealt with the product interface is wrong because it ignores that UX goes beyond that (Merholz, 2007).

The international standard on ergonomics of human-system interaction, ISO 9241-210, defines UX as "a person's perceptions and responses that result from the use or anticipated use of a product, system or service" (DIS, 2010). The ISO definition summarizes somehow what is stated by the literature including all the users' emotions, beliefs, preferences, perceptions, physical and psychological responses, behaviours, and accomplishments that happen before, during and after the experience.

Based on the discussions above and the references that follow in the bullet lists below, the authors tried to individuate least contrasted UX notions. They concluded that it is possible to group into two main foci the patterns and recurring attributes that emerge from UX definitions and meanings: fundamental elements of interaction and typologies of experience (Figure 1). The former has been plainly individuated by (Law et al., 2009), who subdivided it into three main pillars: the user, the system, and the context of use.

- The user refers to everything concerning the involved person and their inner state (Mäkelä and Fulton Suri, 2001; Hassenzahl and Tractinsky, 2006; Sward and Macarthur, 2007; Law and van Schaik, 2010; Kuniavsky, 2010; Córdoba-Cely and Alatriste-Martínez, 2013).

- The system is used here as a broader concept that refers to artefacts (Belk, 1988; Law and van Schaik, 2010), interactive products (Alben, 1996; Karapanos et al., 2009; McNamara and Kirakowski, 2006), technologies (McCarthy and Wright, 2004), services (Sward and Macarthur, 2007), interfaces (Hassenzahl, 2010).

- Most of the contributions agree about the third pillar, which is the context of use. Every UX is strongly influenced by the context where it takes place (Alben, 1996; Mäkelä and Fulton Suri, 2001; McCarthy and Wright, 2004; Hassenzahl and Tractinsky, 2006; Sward and Macarthur, 2007; Law and van Schaik, 2010; Rebelo et al., 2012). The context of use can be intended as a generic variable considered when it comes to UX, but it can also have specific definitions. The context can be intended also as:

○ space and time (Hassenzahl, 2010; McCarthy and Wright, 2004; Sward and Macarthur, 2007);

- environment or physical space (McCarthy and Wright, 2004; Hassenzahl and Tractinsky, 2006; Sward and Macarthur, 2007; Hassenzahl, 2010);

- physical instrumental context, such as technologies and visualization methods involved (Rebelo et al., 2012);

- social and cultural context (Rebelo et al., 2012).

These three elements (user, system, and context of use) are the bases of an experience that can be considered as a collective phenomenon (Battarbee and Koskinen, 2005) or as an individual phenomenon (Goto, 2004). From the literature, three main categories of experience can be identified to describe both individual and collective UXs: ergonomic, cognitive, and emotional.

- Ergonomic experience includes aspects such as usability (Alben, 1996; Sutcliffe, 2009), effectiveness (Alben, 1996; Kuniavsky, 2010; Norman and Nielsen, 2017), affordances (Pucillo and Cascini, 2014).

- Cognitive experience deals with perception (Alben, 1996; Goto, 2004; McCarthy and Wright, 2004; Colbert, 2005; Kuniavsky, 2010) and, specifically, how the user perceives the exteriority and aesthetics of a system (Hassenzahl, 2004; Hekkert, 2006; Desmet and Hekkert, 2007; Norman and Nielsen, 2017).

- Emotional experience includes all the emotional components emphasized by (Norman et al., 1995; Alben, 1996; McCarthy and Wright, 2004; Desmet and Hekkert, 2007; Kuniavsky, 2010). Emotions refers also to the hedonic side, related to the pleasantness of use and possession of a certain object (Norman and Nielsen, 2017; Sutcliffe, 2009). This is evident when the intimate connection brings enrichment and personal growth to the user who owns it (Hassenzahl, 2004) or as a personal expression of user's own values (Belk, 1988).

Based on the types of experience and the pillars or focus factors, a holistic view of the UX is illustrated in Figure 1. 


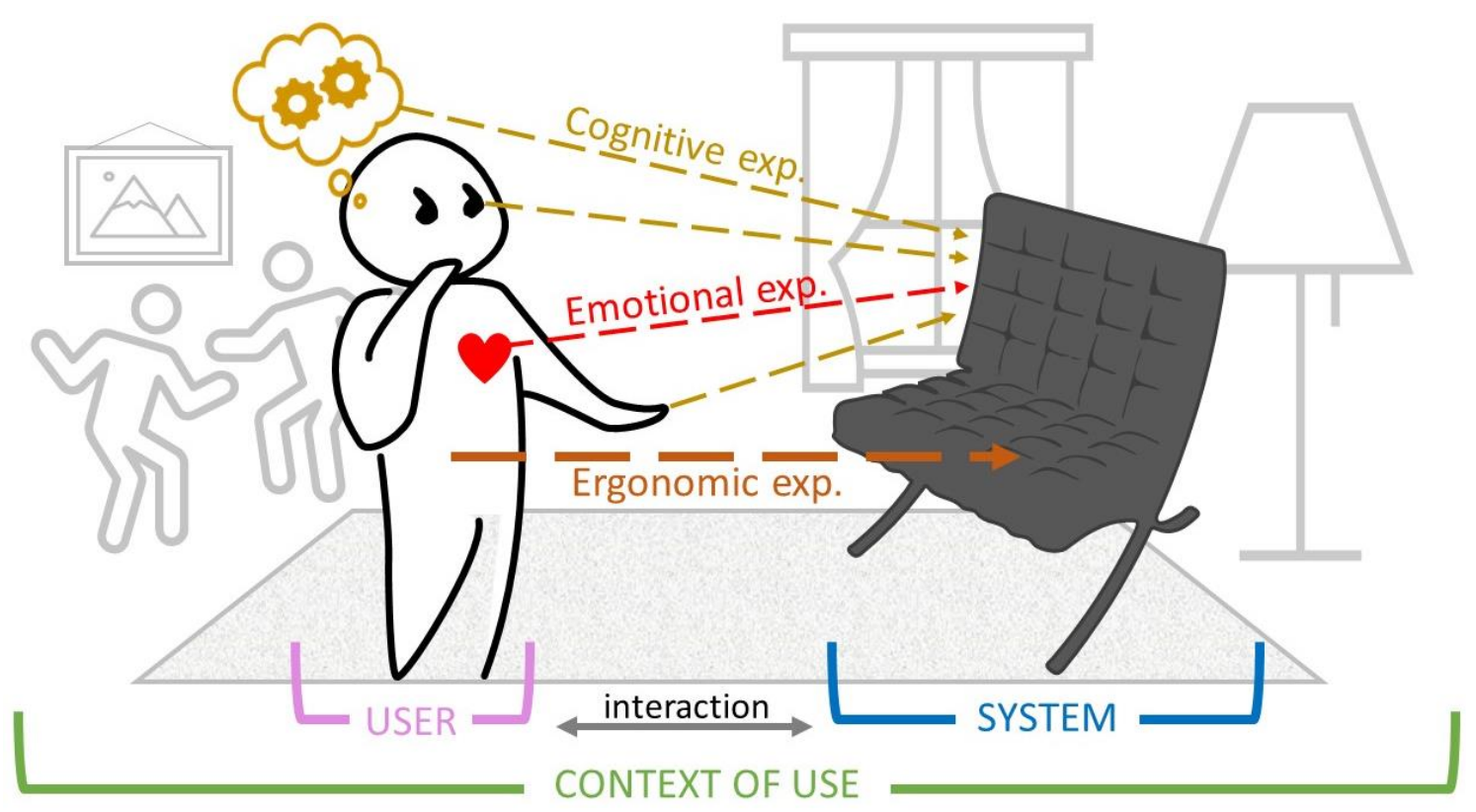

Figure 1: Representation of the two-focus dimensions of the user experience emerging from the definitions in the literature.

The authors do not claim that all the individuated classes are independent, e.g. emotions can arise as a result of a cognitive or sensorial process. Indeed, a slight change of these variables can have a meaningful impact on the user-product interaction, and this might lead to a completely different experience (Hassenzahl, 2010). The scholars suggest designers be aware of those patterns, their abstraction and further application, because these are at the heart of the experience design.

\section{A FRAMEWORK FOR CLASSIFYING CONTRIBUTIONS IN UX DESIGN}

As mentioned, it was in the authors' intention to test if the two foci, which were inferred by analysing the background of theoretical studies on UX (in design and beyond), could be appropriate to describe studies in product and engineering design. To the scope, it is worth pointing out that UX is usually understood as an asset of the design world. However, it has been mostly applied in restricted areas involving ICT technologies and computer science, such as human-computer interaction, web design or web app design, which might have limited its outreach to interface design, affordances and basic functionalities.

Based on the foci, a reference framework was created to describe and classify UX studies in design. The framework simply combines the dimensions of the foci (three each and "other" in case those do not apply) on two axes (see Table 1). Therefore, the two foci were considered independent. Because of the inductive process leading to the creation of the framework, the authors considered it just as a preliminary reference to test the possibility to identify the main features of UX studies in design. If successful, future research can opt to consider the classification criteria behind the framework as a taxonomy able to support a holistic view on UX in design.

The classification framework was then used to categorize UX applications in engineering and product design: ICT systems could be ascribable to a comprehensive meaning of product just when an overall experience with the whole product was dealt with and this was not restricted to interface and web design.

The selection of a sample of convenience of studies followed. As the objective is here to test the effectiveness and usability of the framework, the authors intended to collect a preliminary set of relevant contributions; as such, the here described activity cannot be considered a review or a state-of-the-art analysis. The collection of relevant papers took place by first collecting all Scopus-indexed journal articles reporting the term "User Experience" in their title, abstract and keywords, and the term "design" in the source title. The results were restricted to engineering, art and social disciplines, giving rise to a set of 301 articles. Out of these outcomes, after reading abstracts, the authors considered only those articles in which UX was one of the main topics of the contributions, leading to a smaller subset of 80 articles. Subsequently, analysing the whole text, the authors further filtered the results and selected those articles in which experiments and practical case studies of UX design were described involving products and physical artefacts. The final sample was constituted by 47 articles. 
The articles belonging to the final sample were classified along the dimensions of the two foci, as apparent in Table 1. More dimensions were attributed when multiple pillars or typologies of experiences were made explicit in the articles.

In order to make the process repeatable and to compensate for the mentioned overlaps among classes, the authors used the following criteria to identify those dimensions that were predominantly dealt with in the analysed studies. As for pillars and focus factors, the dimensions were assigned in the following circumstances.

- User: the paper focuses on users, design for users, describes applications of user-centred design, and/or builds UX on users' needs, users' expectations.

- System: the core aspect of the UX is the product or system, the paper describes UX-oriented new product development processes and/or design methods.

- Context: the environment (physical or virtual), situation, culture, social context, time, background, and knowledge of the users involved in the design process are at the backbone of the UX study.

- Other: none of the above factors in play are specified or easily inferable.

As for typologies of UX, the dimensions were assigned in the following circumstances.

- Ergonomic: there is a clear focus on the interaction between the human and the system (usability, performance, affordances, effectiveness, users' behaviour).

- Cognitive: the focus is on how humans perceive, understand, and know a product/system (perception, aesthetic, appearance).

- Emotions: the paper concentrates on how the users feel, their inner state and engagement in terms of feelings, empathy, pleasure, aspirations, hedonistic values, social values, affection, appreciation.

- Other: no specific aspects of the UX are focused on.

The classification was performed by the two authors by following a consensual approach.

Table 1. Classification of the collected studies of UX in engineering and product design according to pillars (columns) and experiences (rows)

\begin{tabular}{|c|c|c|c|c|}
\hline & Pillar: User & Pillar: System & Pillar: Context & $\begin{array}{l}\text { Pillar: } \\
\text { Other }\end{array}$ \\
\hline $\begin{array}{l}\text { Typology } \\
\text { of UX: } \\
\text { Ergonomic }\end{array}$ & $\begin{array}{l}\text { (Belz, 2006; Torres } \\
\text { et al., 2009; Williams } \\
\text { et al., 2011; Keinonen, } \\
\text { 2010; Lockton et al., } \\
\text { 2012; Kim and } \\
\text { Christiaans, 2012; van } \\
\text { der Bijl-Brouwer and } \\
\text { van der Voort, 2014; } \\
\text { Hoyos-Ruiz et al., 2017) }\end{array}$ & $\begin{array}{l}\text { (Nyber and Kempic, } \\
\text { 2006; Johnston } \\
\text { et al., 2008; Nam } \\
\text { et al., 2009; Yeh } \\
\text { et al., 2010; Crilly, } \\
\text { 2011; Wilkinson } \\
\text { and De Angeli, } \\
\text { 2014; Cor and } \\
\text { Zwolinski, 2015; } \\
\text { Cruz Mendoza } \\
\text { et al., 2015; Wu and } \\
\text { Smith, 2015; Wu } \\
\text { and Pillan, 2017) }\end{array}$ & $\begin{array}{c}\text { (Ingram, 1984; } \\
\text { Chamorro-Koc et al., } \\
\text { 2008; Johnston et al., } \\
\text { 2008; Kim and } \\
\text { Christiaans, 2012; } \\
\text { Ferrise, Bordegoni, } \\
\text { et al., 2013; van der } \\
\text { Bijl-Brouwer and van } \\
\text { der Voort, 2014; } \\
\text { Normark and } \\
\text { Gustafsson, 2014; } \\
\text { Hoyos-Ruiz et al., } \\
\text { 2017) }\end{array}$ & $\begin{array}{r}\text { (Ludden } \\
\text { and } \\
\text { Rompay } \\
\text {, 2015) }\end{array}$ \\
\hline $\begin{array}{l}\text { Typology } \\
\text { of UX: } \\
\text { Cognitive }\end{array}$ & $\begin{array}{l}\text { (Markussen, 2009; Siu } \\
\text { et al., 2011; Kim and } \\
\text { Christiaans, 2012; } \\
\text { Gkouskos et al., 2014; } \\
\text { Sansoni et al., 2016; } \\
\text { Hoyos-Ruiz et al., 2017) }\end{array}$ & $\begin{array}{c}\text { (Markussen, 2009; } \\
\text { Bongard-Blanchy } \\
\text { et al., 2015; Karana } \\
\text { et al., 2015; Zuo } \\
\text { et al., 2016; Merter, } \\
\text { 2017) }\end{array}$ & $\begin{array}{l}\text { (Chamorro-Koc et al., } \\
\text { 2008; Markussen and } \\
\text { Krogh, 2008; Jallouli } \\
\text { and Moreau, 2009; } \\
\text { Bagnasacco, 2011; } \\
\text { Zhou et al., 2011; Kim } \\
\text { and Christiaans, 2012; } \\
\text { Ferrise, Graziosi, et al., } \\
\text { 2013; Ferrise, } \\
\text { Bordegoni, et al., } \\
\text { 2013; Bongard- } \\
\text { Blanchy et al., 2015; } \\
\text { da Silva et al., 2015; } \\
\text { Karana et al., 2015; } \\
\text { Hoyos-Ruiz et al., } \\
\text { 2017) }\end{array}$ & $\begin{array}{r}\text { (Ludden } \\
\text { and } \\
\text { Rompay } \\
, 2015)\end{array}$ \\
\hline
\end{tabular}




\begin{tabular}{|c|c|c|c|}
\hline $\begin{array}{l}\text { Typology } \\
\text { of UX: } \\
\text { Emotional }\end{array}$ & $\begin{array}{l}\text { (Belz, 2006; Markussen, } \\
\text { 2009; Nurkka et al., } \\
\text { 2009; Keinonen, 2010; } \\
\text { Williams et al., 2011; } \\
\text { Sansoni et al., 2016; } \\
\text { Ghajargar et al., 2017; } \\
\text { McCarthy et al., 2017; } \\
\text { Pettersson, 2017; Yoon } \\
\text { et al., 2017) }\end{array}$ & $\begin{array}{c}\text { (Belz, 2006; } \\
\text { Markussen, 2009; } \\
\text { Postma et al., 2012; } \\
\text { Karana et al., 2015; } \\
\text { Zuo et al., 2016; } \\
\text { Yoon et al., 2017) }\end{array}$ & $\begin{array}{l}\text { (Bagnasacco, 2011; } \\
\text { Zhou et al., 2011; } \\
\text { Fokkinga and Desmet, } \\
\text { 2013; da Silva et al., } \\
\text { 2015; Karana et al., } \\
\text { 2015; Pettersson, } \\
\text { 2017) }\end{array}$ \\
\hline $\begin{array}{l}\text { Typology } \\
\text { of UX: } \\
\text { Other }\end{array}$ & $\begin{array}{l}\text { (Kim et al., 2016; Oygür, } \\
\text { 2017) }\end{array}$ & $\begin{array}{c}\text { (Buskermolen et al., } \\
\text { 2015) }\end{array}$ & (Oygür, 2017) \\
\hline
\end{tabular}

\section{DISCUSSIONS AND IMPLICATIONS}

The results of the classification and a numerical analysis thereof are discussed below, where numbers in brackets identify the quantity of articles belonging to classes.

As for the total number of papers for each pillar, rather balanced figures emerge. The context is the focus factor with the largest number of contributions (27), while the system has the lowest (23). The box "other" (2) can be considered negligible.

The same considerations have been done for the three experiences. The ergonomic class presents the largest number of papers (27), while the emotional has the lowest (22). Also in this case, the class representing "other" can be neglected - as the same conclusion can be made for pillars, the authors claim that the classification well applies to UX studies in design. The balance of the total distribution of the papers denotes a lack of a predominant element among experiences, similarly to what has been pointed out with respect to pillars. The number of contributions per each combination pillarexperience has been considered too. The data shows that there are some combinations with larger and smaller numbers of contributions. The largest number of papers is in the "context-cognitive" combination (12), followed by "system-ergonomic" (11) and "user-emotional" (10). The fewest combinations are "user-cognitive" (6) and "context-emotional" (6) combination of factors, while "system-cognitive" groups 5 papers only.

Although the total number of contributions per pillar and per experience is balanced, data shows that some pillars in correlation to specific experiences have been considered more frequently. It can be noted that no overlaps of pillars and experiences are found in the most recurring three combinations. Some contributions have been attributed to multiple classes of the framework. Most of the papers attributed to multiple dimensions regarded one of the two foci of the framework only. In particular, 10 papers involved two pillars, but none of them presented all the pillars. On the other hand, 14 contributions presented more than one typology of experience. Among them, only one dealt with all the ergonomic, cognitive and emotional experiences at the same time (Zuo et al., 2016). Few papers combine multiple pillars with multiple experiences. However, no contribution considers all the aspects of the UX simultaneously in a holistic way.

\section{MAIN FINDINGS AND FINAL REMARKS}

The authors started this work collecting authoritative definitions of UX in the literature. Although scholars provide a variety of definitions with different nuances, it is still possible to spot some recurring patterns. The authors individuated two main foci ascribable to the UX: pillars or fundamental elements of interaction (user, system, context) and typologies of experiences (ergonomic, cognitive, emotional).

A tentative framework has been created to classify a first sample of contributions involving the application of UX in engineering and product design. The aim of this classification was twofold. First, it made it possible to individuate the UXs that emerge most frequently and the most studied ones in the design field. Second, it enabled the understanding of how different aspects of UX in design are connected. Despite some inherent subjectivity in the classification process, the taxonomy can be deemed sufficiently robust, as the majority of UX contributions could be easily classified and just a few ones could not be categorized. A validation of the framework could take place if different research 
groups would be willing to verify the convergence of their classification with the authors' ones. This could lead to reformulate the framework and the foci, if needed.

Based on the outcomes of the classification and despite the consideration of a restricted number of studies, it can be stated that the design field has paid large attention on all the pillars and typologies of experience. This has taken place with an overall balance among the classes of the two foci. The same balance cannot be claimed when combinations across the classes of the foci are considered. For instance, the context, i.e. the most dealt with UX pillar, was predominantly studied in conjunction with cognitive UXs. Here, it is also worth noting that the context is attributed a plurality of meanings, e.g. press, and tools and representations used in UX experiments, e.g. (Berni et al., 2020), and that a differentiation among them could lead to more insightful results. Actually, a considerable limitation of the framework is the difficulty to circumscribe the pillars, whose definition can be still open to debate, e.g. the difference stances on emotions in design.

Rather unsurprisingly, other popular combinations were "system-ergonomic" and "user-emotional". The emergence of very frequent combinations with no overlap in terms of foci seemingly lays bare the existence of separate domains of UX studies in design. In this view, UX in design might be considered as a common area of interest for design cognition, emotional design, and ergonomic studies on industrial products. In this view, UX would not be considered as an autonomous and self-standing domain in design. Although this conclusion may not be proven at the present stage, the authors would rather recommend steering UX research in design towards a more holistic perspective - the present paper is plainly, in its intentions, a support in this direction. Markedly, some of the analysed contributions consider more types of experience and/or pillars simultaneously; however, no paper addresses the whole articulation of classes across the two foci. Nor any paper aims to propose an approach to study the UX in a holistic way. This fact can be considered as a literature gap to be tackled in the future.

In this respect, the proposed taxonomy is a candidate reference for future researchers willing to finetune methodologies and experiments capable of capturing all the main aspects involved in a UX with a design, and their inherent interconnections, e.g. a positive ergonomic experience with a product should give rise to a likewise positive emotional experience. It is in authors' intention to contribute to these developments. The framework can also be intended as a landmark for a systematic review of UX studies in design. It can be noted that the sample of contributions chosen here was aimed to verify the goodness of the taxonomy and infer preliminary results, but these studies well represent a starting point for a comprehensive state-of-the-art analysis.

\section{REFERENCES}

Alben, L. (1996), "Quality of experience: defining the criteria for effective interaction design", Interactions, Vol. 3 No. 3, pp. 11-15.

Bagnasacco, M. (2011), "Sustainable Process in Design Thinking: Beyond Aesthetics and the Ordinary.", Design Principles \& Practice: An International Journal, Vol. 5 No. 6, pp. 29-45.

Battarbee, K. and Koskinen, I. (2005), “Co-experience: user experience as interaction”, CoDesign, Vol. 1 No. 1, pp. 5-18.

Belk, R.W. (1988), "Possessions and the Extended Self”, Journal of Consumer Research, Vol. 15 No. 2, pp. 139168.

Belz, S.M. (2006), "Development of a New Photographic Experience”, Ergonomics in Design, Vol. 14 No. 4, pp. $19-24$.

Berni, A., Maccioni, L. and Borgianni, Y. (2020), "Observing Pictures and Videos of Creative Products: An Eye Tracking Study”, Applied Sciences, Vol. 10 No. 4, p. 1480.

van der Bijl-Brouwer, M. and van der Voort, M. (2014), "Understanding design for dynamic and Diverse Use Situations", Vol. 8 No. 2, pp. 29-42.

Bongard-Blanchy, K., Bouchard, C., Bonnardel, N., Lockner, D. and Aoussat, A. (2015), “User experience dimensions in product design: a consolidation of what academic researchers know and what design practitioners do", Journal of Design Research, Vol. 13 No. 2, pp. 107-124.

Buskermolen, D., Terken, J.M.B. and Eggen, J.H. (2015), "The co-constructing stories method: feedback of designers on use of the method in real design cases", The International Journal of Design Management and Professional Practice, Vol. 8 No. 2, pp. 17-28.

Chamorro-Koc, M., Popovic, V. and Emmison, M. (2008), "Using visual representation of concepts to explore users and designers' concepts of everyday products", Design Studies, Vol. 29 No. 2, pp. 142-159.

Colbert, M. (2005), "User experience of communication before and during rendezvous: interim results", Personal and Ubiquitous Computing, Vol. 9 No. 3, pp. 134-141. 
Cor, E. and Zwolinski, P. (2015), “A Protocol to Address User Behavior in the Eco-Design of Consumer Products", Journal of Mechanical Design, Vol. 137 No. 7, available at:https://doi.org/10.1115/1.4030048.

Córdoba-Cely, C. and Alatriste-Martínez, Y. (2013), "Visualization of Knowledge Domains in the User Experience", The International Journal of Visual Design, Vol. 6 No. 1, pp. 15-26.

Crilly, N. (2011), "Do Users Know What Designers Are Up To? Product Experience and the Inference of Persuasive Intentions", International Journal of Dsign, Vol. 5 No. 3, pp. 1-15.

Cruz Mendoza, R., Bianchi-Berthouze, N., Romero, P. and Lavín, G.C. (2015), “A classification of user experience frameworks for movement-based interaction design”, The Design Journal, Vol. 18 No. 3, pp. 393-420.

Desmet, P. and Hekkert, P. (2007), "Framework of Product Experience”, International Journal of Design, Vol. 1, pp. 57-66.

DIS, I. (2010), “9241-210: 2010. Ergonomics of human system interaction-Part 210: Human-centred design for interactive systems (formerly known as 13407)", International Standardization Organization (ISO). Switzerland.

Ferrise, F., Bordegoni, M. and Graziosi, S. (2013), “A Method for Designing Users’ Experience with Industrial Products based on a Multimodal Environment and Mixed Prototypes”, Computer-Aided Design and Applications, Vol. 10 No. 3, pp. 461-474.

Ferrise, F., Graziosi, S., Furtado, G.P., Bordegoni, M. and Bongini, D. (2013), "Re-engineering of the Haptic Feedback of a Dishwasher Door", Computer-Aided Design and Applications, Vol. 10 No. 6, pp. 995-1006.

Fokkinga, S.F. and Desmet, P.M.A. (2013), “Ten Ways to Design for Disgust, Sadness, and Other Enjoyments: A Design Approach to Enrich Product Experiences with Negative Emotions", International Journal of Design, Vol. 7 No. 1, available at: http://www.ijdesign.org/index.php/IJDesign/article/view/1180 (accessed 11 November 2020).

Ghajargar, M., Longo, L., Gargiulo, E. and Giannantonio, R. (2017), "Empathy Workshop: When Project team and Pilot Users Exchange Experiences", The Design Journal, Vol. 20 No. sup1, pp. S3837-S3848.

Gkouskos, D., Normark, C.J. and Lundgren, S. (2014), "What drivers really want: Investigating dimensions in automobile user needs", International Journal of Design, Vol. 8 No. 1, pp. 59-71.

Goto, K. (2004), "Brand Value and the User Experience", Digital Web, 14 July, available at: http://www.digitalweb.com/articles/brand_value_and_the_user_experience/ (accessed 14 October 2020).

Hassenzahl, M. (2004), "The Interplay of Beauty, Goodness, and Usability in Interactive Products", HumanComputer Interaction, Vol. 19 No. 4, pp. 319-349.

Hassenzahl, M. (2010), “Experience Design: Technology for All the Right Reasons”, Synthesis Lectures on Human-Centered Informatics, Vol. 3 No. 1, pp. 1-95.

Hassenzahl, M. and Tractinsky, N. (2006), "User experience - a research agenda", Behaviour \& Information Technology, Vol. 25 No. 2, pp. 91-97.

Hekkert, P. (2006), "Design aesthetics: principles of pleasure in design”, Psychology Science, Vol. 48 No. 2, pp. $157-172$.

Hoyos-Ruiz, J., Martínez-Cadavid, J.F., Osorio-Gómez, G. and Mejía-Gutiérrez, R. (2017), "Implementation of ergonomic aspects throughout the engineering design process: Human-Artefact-Context analysis", International Journal on Interactive Design and Manufacturing (IJIDeM), Vol. 11 No. 2, pp. 263-277.

Ingram, J. (1984), "Designing the spatial experience", Design Studies, Vol. 5 No. 1, pp. 15-20.

Jallouli, J. and Moreau, G. (2009), "Virtual reality as a landscape decision-making tool: The wind turbines' case", Int. J. Distrib. Syst. Technol, Vol. 16, pp. 73-88.

Johnston, A., Candy, L. and Edmonds, E. (2008), "Designing and evaluating virtual musical instruments: facilitating conversational user interaction”, Design Studies, Vol. 29 No. 6, pp. 556-571.

Karana, E., Rognoli, V. and Zeeuw Van Der Laan, A. (2015), "Material driven design (MDD): A method to design for material experiences", International Journal of Dsign, available at: http://index.ijdesign.org/index.php/IJDesign/article/view/1965 (accessed 10 November 2020).

Karapanos, E., Zimmerman, J., Forlizzi, J. and Martens, J.-B. (2009), "User experience over time: an initial framework", Proceedings of the SIGCHI Conference on Human Factors in Computing Systems, Association for Computing Machinery, New York, NY, USA, pp. 729-738.

Karvonen, K. (2000), "The beauty of simplicity", Proceedings on the 2000 Conference on Universal Usability, Association for Computing Machinery, New York, NY, USA, pp. 85-90.

Keinonen, T. (2010), "Protect and appreciate - Notes on the Justification of User-Centered Design", p. 11.

Kim, C. and Christiaans, H. (2012), "Soft' usability problems with consumer electronics: the interaction between user characteristics and usability", Journal of Design Research, Vol. 10 No. 3, pp. 223-238.

Kim, E., Chung, J., Beckman, S. and Agogino, A.M. (2016), "Design Roadmapping: A Framework and Case Study on Planning Development of High-Tech Products in Silicon Valley”, Journal of Mechanical Design, Vol. 138 No. 101106, available at:https://doi.org/10.1115/1.4034221.

Kuniavsky, M. (2010), Smart Things: Ubiquitous Computing User Experience Design, Elsevier. 
Law, E., Roto, V., Vermeeren, A.P.O.S., Kort, J. and Hassenzahl, M. (2008), “Towards a shared definition of user experience", CHI '08 Extended Abstracts on Human Factors in Computing Systems, Association for Computing Machinery, New York, NY, USA, pp. 2395-2398.

Law, E.L.-C., Roto, V., Hassenzahl, M., Vermeeren, A.P.O.S. and Kort, J. (2009), "Understanding, scoping and defining user experience: a survey approach", Proceedings of the SIGCHI Conference on Human Factors in Computing Systems, Association for Computing Machinery, New York, NY, USA, pp. 719-728.

Law, E.L.-C. and van Schaik, P. (2010), "Modelling user experience - An agenda for research and practice", Interacting with Computers, Vol. 22 No. 5, pp. 313-322.

Lockton, D., Harrison, D. and Stanton, N.A. (2012), "Models of the user: designers' perspectives on influencing sustainable behaviour", Journal of Design Research, Vol. 10 No. 1-2, pp. 7-27.

Ludden, G.D.S. and Rompay, T.J.L. van. (2015), "How does it feel? Exploring touch on different levels of product experience”, Journal of Engineering Design, Vol. 26 No. 4-6, pp. 157-168.

Mäkelä, A. and Fulton Suri, J. (2001), “Supporting users' creativity: Design to induce pleasurable experiences”, Proceedings of the International Conference on Affective Human Factors Design, pp. 387-394.

Markussen, T. (2009), "How Emotional Structures May Change Expectations of Technology Use in Hospitals", p. 13.

Markussen, T. and Krogh, P.G. (2008), "Mapping Cultural Frame Shifting in Interaction Design with Blending Theory", International Journal of Design, Vol. 2 No. 2, pp. 5-17.

McCarthy, G.M., Ramírez, E.R.R. and Robinson, B.J. (2017), "Design Experiments. Identifying areas for intervention and designing medical technology for adolescents and young adults with type 1 diabetes", The Design Journal, Vol. 20 No. sup1, pp. S2044-S2056.

McCarthy, J. and Wright, P. (2004), Technology as Experience, Vol. 11, MIT Press, Cambridge, Massachusetts, United States.

McNamara, N. and Kirakowski, J. (2006), "Functionality, usability, and user experience: three areas of concern", Interactions, Vol. 13 No. 6, pp. 26-28.

Merholz, P. (2007), "Peter in Conversation with Don Norman About UX \& Innovation | Adaptive Path", available at: https://web.archive.org/web/20131207190602/http://www.adaptivepath.com/ideas/e000862/ (accessed 13 October 2020).

Merter, S. (2017), "Synesthetic Approach in the Design Process for Enhanced Creativity and Multisensory Experiences", The Design Journal, Vol. 20 No. sup1, pp. S4519-S4528.

Nam, T.-J., Park, S. and Verlinden, J. (2009), “A model to conceptualize interactivity”, International Journal on Interactive Design and Manufacturing (IJIDeM), Vol. 3 No. 3, pp. 147-156.

Norman, D., Miller, J. and Henderson, A. (1995), "What You See, Some of What's in the Future, And How We Go About Doing It: HI at Apple Computer", presented at the CHI '95 MOSAIC OF CREATIVITY, p. 1.

Norman, D. and Nielsen, J. (2017), “The Definition of User Experience (UX)”, Nielsen Norman Group, available at: https://www.nngroup.com/articles/definition-user-experience/ (accessed 14 October 2020).

Normark, C.J. and Gustafsson, A. (2014), "Design and evaluation of a personalisable user interface in a vehicle context”, Journal of Design Research, Vol. 12 No. 4, pp. 308-329.

Nurkka, P., Kujala, S. and Kemppainen, K. (2009), “Capturing users' perceptions of valuable experience and meaning”, Journal of Engineering Design, Vol. 20 No. 5, pp. 449-465.

Nyber, P. and Kempic, J. (2006), “Transforming the Laundry Process”, Ergonomics in Design, Vol. 14 No. 2 , pp. 16-21.

Oygür, I. (2017), "User, Research, and Practice. Learning from Design Consultancies”, The Design Journal, Vol. 20 No. sup1, pp. S4621-S4631.

Pettersson, I. (2017), “Travelling from Fascination to New Meanings":, Vol. 11 No. 2, p. 11.

Postma, C., Zwartkruis-Pelgrim, E., Daemen, E. and Du, J. (2012), "Challenges of Doing Empathic Design: Experiences from Industry", International Journal of Dsign, available at: http://www.ijdesign.org/index.php/IJDesign/article/view/1008 (accessed 10 November 2020).

Pucillo, F. and Cascini, G. (2014), "A framework for user experience, needs and affordances", Design Studies, Vol. 35 No. 2, pp. 160-179.

Rebelo, F., Noriega, P., Duarte, E. and Soares, M. (2012), "Using Virtual Reality to Assess User Experience", Human Factors, Vol. 54, pp. 964-82.

Roto, V., Law, E., Vermeeren, A.P.O.S. and Hoonhout, J. (2010), USER EXPERIENCE WHITE PAPER Bringing Clarity to the Concept of User Experience, Hoonhout and Research - Delft University of Technology, Dagstuhl, p. 12.

Sansoni, S., Wodehouse, A., McFadyen, A. and Buis, A. (2016), "Utilising the Repertory Grid Technique in Visual Prosthetic Design: Promoting a User-Centred Approach", Journal of Integrated Design and Process Science, Vol. 20 No. 2, pp. 31-46.

da Silva, O., Crilly, N. and Hekkert, P. (2015), "How people's appreciation of products is affected by their knowledge of the designers' intentions", International Journal of Design, Vol. 9, pp. 21-33.

Siu, K.W.M., Ng, A.W.Y. and Chan, C.C.H. (2011), "The Imagery Vividness and Preferences of Older People: Implications for Visualization in Concept Design”, The Design Journal, Vol. 14 No. 4, pp. 413-426. 
Sun, S. and Teng, L. (2017), "Establishing China’s First UX Master Program Based on Applied Psychology Perspective", in Marcus, A. and Wang, W. (Eds.), Design, User Experience, and Usability: Theory, Methodology, and Management, Springer International Publishing, Cham, pp. 767-775.

Sutcliffe, A. (2009), Designing for User Engagement: Aesthetic and Attractive User Interfaces, Morgan \& Claypool Publishers.

Sward, D. and Macarthur, G. (2007), "Making user experience a business strategy”, E. Law et al.(Eds.), Proceedings of the Workshop on Towards a UX Manifesto, Vol. 3, pp. 35-40.

Torres, R.J. (Bob), Heck, M.P., Rudd, J.R. and Kelley, J.F. (Jeff). (2009), "Usability Engineering: 'Best of the Best' Best Practices", Ergonomics in Design, Vol. 17 No. 3, pp. 20-25.

Wilkinson, C.R. and De Angeli, A. (2014), “Applying user centred and participatory design approaches to commercial product development”, Design Studies, Vol. 35 No. 6, pp. 614-631.

Williams, M.A., Attridge, A. and Pitts, M. (2011), "User-centred design and evaluation of automotive seat adjustment controls", International Journal of Vehicle Design, Vol. 55 No. 2-4, pp. 119-138.

Wu, C.-M. and Smith, S. (2015), "A haptic keypad design with a novel interactive haptic feedback method", Journal of Engineering Design, Vol. 26 No. 4-6, pp. 169-186.

Wu, Y. and Pillan, M. (2017), "From respect to change user behaviour. Research on how to design a next generation of smart home objects from User Experience and Interaction Design", The Design Journal, Vol. 20 No. sup1, pp. S3884-S3898.

Yeh, K.-C. (Martin), Gregory, J.P. and Ritter, F.E. (2010), “One Laptop per Child: Polishing Up the Xo Laptop User Experience”, Ergonomics in Design, Vol. 18 No. 3, pp. 8-13.

Yoon, J., Pohlmeyer, A.E. and Desmet, P.M.A. (2017), "EmotionPrism: a design tool that communicates 25 pleasurable human-product interactions", Journal of Design Research, Vol. 15 No. 3-4, pp. 174-196.

$\mathrm{Yu}, \mathrm{N}$. and Kong, J. (2016), "User experience with web browsing on small screens: Experimental investigations of mobile-page interface design and homepage design for news websites”, Information Sciences, Vol. 330, pp. 427-443.

Zhou, F., Xu, Q. and Jiao, R.J. (2011), "Fundamentals of product ecosystem design for user experience”, Research in Engineering Design, Vol. 22 No. 1, pp. 43-61.

Zuo, H., Jones, M., Hope, T. and Jones, R. (2016), "Sensory Perception of Material Texture in Consumer Products", The Design Journal, Vol. 19 No. 3, pp. 405-427. 